\title{
Liver damage and protective effect of high density lipoprotein cholesterol
}

\author{
Jukka T Salonen
}

Raised

concentrations

of HDL

cholesterol

may lose their

protective

effect against

coronary

events in

people with

raised liver

enzyme

activity. The

implications

of this finding

for trials of

lipid drugs

need further

investigation

Research Institute

of Public Health,

Department of

Public Health and

General Practice,

University of

Kuopio, Box 1627,

FIN-70211 Kuopio,

Finland

Jukka T Salonen

professor of

epidemiology

jukka.salonen@

uku.fi

BMJ 2003;327:1082-3

Prospective population studies have shown that a raised concentration of high density lipoprotein (HDL) cholesterol is associated with a reduced incidence of coronary events and atherosclerotic progression..$^{12}$ According to one paradigm any raised concentration of HDL cholesterol is beneficial to health. ${ }^{1}$ This is, however, challenged by two unexplained observations. Firstly, in populations with heavy alcohol intake a high concentration of HDL cholesterol is not associated with reduced coronary and total mortality. ${ }^{3}$ Secondly, in such populations a high concentration of HDL cholesterol is not associated with effective reverse cholesterol transport. ${ }^{4}$ Alcohol raises concentrations of both HDL cholesterol and liver transaminase.

\section{Participants, methods, and results}

We tested the hypothesis that a raised concentration of HDL cholesterol caused by liver activation and damage is not protective against coronary heart disease in the Kuopio ischaemic heart disease (KIHD) risk factor study, a prospective cohort study. ${ }^{12}$ The study sample comprised men from eastern Finland aged 42, 48, 54, and 60 years; 2682 men were examined during 1984-9. Relevant baseline measurements were available for 2464 men. The average follow up time was 12.4 years, resulting in more than 30000 person years of follow up. Activity of $\gamma$-glutamyltransferase was determined according to the Scandinavian recommendation. ${ }^{5}$ The cut-off for raised activity (60 IU/l) is the reference value determined by the laboratory. The long term repeat correlation in 748 participants in our study was 0.33 $(\mathrm{P}<0.001)$. Mean alcohol intake was $172 \mathrm{~g}$ /week in men with raised $\gamma$-glutamyltransferase activity and 67 in men without raised activity $(\mathrm{P}<0.001)$. The measurement of cholesterol concentrations in serum lipoproteins, other risk factors (see table), and the classification of acute coronary events and deaths have been described. ${ }^{12}$
Among men whose liver enzyme

( $\gamma$-glutamyltransferase) activity was within the normal range, a raised concentration of HDL cholesterol was associated with a risk reduction for coronary events of $47 \%$ (95\% confidence interval $19-65 \%$ ) per each $\mathrm{mmol} / \mathrm{l}$ (table). However, in men with raised liver enzyme activity the risk increased 3.0-fold (1.1-fold to 8.3-fold) per each $\mathrm{mmol} / \mathrm{l}$ of HDL cholesterol. These relative risks differed significantly from each other $(\mathrm{P}=0.002)$. The addition of any measured factor, including several measurements of alcohol intake, as a covariate singly or jointly did not affect this difference. Similarly, the relative risks for coronary, all cardiovascular, and all cause death were significantly different between men without and men with raised liver enzyme activity (table). The proportion of the second subfraction of total HDL cholesterol $\left(\mathrm{HDL}_{2}\right)$ was identical $(65 \%)$ in both groups.

\section{Comment}

High serum concentrations of HDL lose their protective effect against coronary heart disease in men with raised liver enzyme activity. This effect modification was observed also for cardiovascular and total mortality. If confirmed, our observations imply that raised concentrations of HDL cholesterol are not always beneficial. It can be speculated that if there is raised liver enzyme activity or liver damage, a high concentration of HDL cholesterol is an indicator of the raised enzyme activity and may not function in reverse cholesterol transport nor as an antioxidant as it would under normal conditions. Raised liver enzyme activity and liver damage may be caused by heavy alcohol intake, drugs, hepatotoxic nutrients, or contaminants in food.

Changes to measurements of liver transaminase in clinical trials with lipid drugs should be published. It would also be important to analyse how raised transaminase activity might modify the effects of these drugs in preventing atherosclerotic progression and coronary events. Eventually, assessment of liver

Relative risk of acute coronary events, coronary, cardiovascular, and any death, per $1 \mathrm{mmol} / \mathrm{l}$ of serum HDL cholesterol, in 2464 men without and with raised liver enzyme activity at baseline in the Kuopio ischaemic heart disease (KIHD) study during 1984-9

\begin{tabular}{|c|c|c|c|c|c|c|c|c|}
\hline \multirow[b]{2}{*}{$\begin{array}{l}\text { Outcome (No of men with each } \\
\text { event) }\end{array}$} & \multicolumn{3}{|c|}{$\begin{array}{l}\text { No raised liver enzyme activity: } \gamma \text {-glutamyltransferase } \\
\qquad 60 \text { IU/I }(n=2253)\end{array}$} & \multicolumn{3}{|c|}{$\begin{array}{l}\text { Raised liver enzyme activity: } \gamma \text {-glutamyltransferase } \\
\qquad 60 \mathrm{IU} / \mathrm{I}(\mathrm{n}=211)\end{array}$} & \multicolumn{2}{|c|}{ Significance of difference } \\
\hline & $\begin{array}{l}\text { Relative risk (No of } \\
\text { men with event) }\end{array}$ & $95 \% \mathrm{Cl}$ & $P$ value & $\begin{array}{l}\text { Relative risk (No of } \\
\text { men with event) }\end{array}$ & $95 \% \mathrm{Cl}$ & $P$ value & Z statistic & $P$ value \\
\hline Acute coronary event $(n=416)$ & $0.53(369)$ & 0.35 to 0.81 & 0.003 & $3.01(47)$ & 1.10 to 8.27 & 0.032 & 3.11 & 0.002 \\
\hline Coronary death $(n=155)$ & $0.54(130)$ & 0.27 to 1.11 & 0.094 & $5.15(25)$ & 1.32 to 20.06 & 0.018 & 2.87 & 0.004 \\
\hline Cardiovascular death $(\mathrm{n}=208)$ & $0.81(177)$ & 0.45 to 1.47 & 0.491 & $4.84(31)$ & 1.50 to 15.60 & 0.008 & 2.67 & 0.008 \\
\hline All cause death $(n=412)$ & $0.93(339)$ & 0.61 to 1.41 & 0.722 & $2.37(73)$ & 1.15 to 4.90 & 0.020 & 2.19 & 0.029 \\
\hline
\end{tabular}

Cox proportional hazards regression models were used separately for men with and without raised liver enzyme activity, adjusted for age, cigarette years, serum apolipoprotein B (mg/l), use of antihypertensive drugs, maximal oxygen uptake $(\mathrm{ml} / \mathrm{kg} \times \mathrm{min})$, history of any atherosclerosis related disease, family history of coronary heart disease, and indicator variables for five examination years. Differences between groups were tested according to Altman and Bland (Altman DG. Bland JM. Interaction revisited: the difference between two estimates. BMJ 2003;326:219). 
function and related genetic variation could be used to predict the efficacy and safety of drugs that raise concentrations of HDL cholesterol.

The author thanks the late Jarmo Pikkarainen and Georg Alfthan, National Public Health Institute of Finland, for measurements of $\gamma$-glutamyltransferase and Kari Seppänen for lipoprotein analyses.

Contributor: JTS initiated the Kuopio ischaemic heart disease (KIHD) risk factor study, analysed the data, wrote the paper, and is the guarantor.

Funding: The KIHD study was funded by research grants from the National Institutes of Health (grant HL 44199 to professor George A Kaplan) and from the Academy of Finland (grants 41471, 1041086, and 2041022 to J T Salonen).

Competing interests: JTS is the inventor in a related patent application (WO 03/052129).
1 Salonen JT, Salonen R, Seppänen K, Rauramaa R, Tuomilehto J. High density lipoprotein, $\mathrm{HDL}_{2}$ and $\mathrm{HDL}_{3}$ subfractions and the risk of acute myocardial infarction: a prospective population study in Eastern Finnish men. Circulation 1991;84:129-39.

2 Salonen JT, Ylä-Herttuala S, Yamamoto R, Butler S, Korpela H, Salonen $\mathrm{R}$, et al. Autoantibody against oxidised LDL and progression of carotid atherosclerosis. Lancet 1992;339:883-7.

3 Perova NV, Oganov RG, Williams DH, Irving SH, Abernathy JR, Deev AD, et al. Association of high-density-lipoprotein cholesterol with mortality and other risk factors for major chronic noncommunicable diseases in samples of US and Russian men. Ann Epidemiol 1995;5:179-85.

4 Liinamaa MJ, Hannuksela ML, Kesäniemi YA, Savolainen MJ. Altered transfer of cholesterol esters and phospholipids in plasma from alcohol abusers. Arterioscler Thromb Vasc Biol 1997;17:2940-7.

5 Committee of Enzymes of the Scandinavian Society for Clinical Chemistry and Clinical Physiology. Recommended method for the determiantion of gamma-glutamyl transferase in blood. Scand J Clin Lab Invest 1976;36:119-25.

(Accepted 4July 2003)

\title{
Number of published systematic reviews and global burden of disease: database analysis
}

\author{
George H Swingler, Jimmy Volmink, John P A Ioannidis
}

Systematic reviews are key to implementing evidence based medicine. ${ }^{1}$ We wondered if the reviews done to date are related to the burden of disease from various conditions. Ideally, evidence should be prioritised for diseases with the greatest global impact.

\section{Methods and results}

We estimated Spearman correlations between the number of systematic reviews in two important databases (the Cochrane database of systematic reviews (CDSR) and the database of abstracts of reviews of effects (DARE)) and the burden of disease (globally and in established market economies) across disease categories. We also estimated the burden of disease for each available review measured in disability adjusted life years (DALYs). ${ }^{23}$ We used 1990 estimates of burden of disease because studies included in systematic reviews would have responded to recent past health needs. Results with estimates from 2000 were similar.

We categorised tar geted diseases in 923 reviews from the CDSR and 1899 reviews from the DARE in issue 4, 2000, of the Cochrane Library using 20 categories of the global burden of disease taxonomy. ${ }^{3}$ We excluded unclassifiable topics (health systems, pain or anaesthesia, general operative techniques, and smoking cessation). To avoid small contributors to burden of disease, a separate analysis retained only the top 10 groups of disease accounting for $>90 \%$ of the global burden of disease. Reviews in the DARE came from high profile general medical journals (173), other general journals (77), specialist journals (1532), or other reports (117). Two independent investigators did categorisations and resolved disagreements by discussion.

We looked for correlation between the number of systematic reviews and the burden of disease. Given the small number of categories, modest differences in estimated correlations between databases and subgroups should not be attributed formal statistical significance.
We categorised 866 reviews from the CDSR and 1639 reviews from the DARE (898 and 1729 disease group entries). Coverage was similar across databases except the CDSR covered maternal and perinatal conditions better. Across disease groups, global DALYs for each review varied between 0.2-33.0 million in the CDSR and 0.1-5.5 million in the DARE. Among the top 10 disease groups, nutritional deficiencies, injuries, respiratory infections, and infectious diseases were most neglected ( $>2$ million global DALYs for each available review in either database).

Burden of disease was modestly correlated with the number of systematic reviews in the CDSR (global $\mathrm{r}=0.54, \quad \mathrm{P}=0.014$; established market economies $\mathrm{r}=0.46, \quad \mathrm{P}=0.041$ ), the DARE (global $\mathrm{r}=0.65$, $\mathrm{P}=0.002$; established market economies $\mathrm{r}=0.76$, $\mathrm{P}<0.001)$ and in subgroups of the DARE.

For the top 10 disease groups, correlations between the number of systematic reviews and the global burden of disease remained unchanged in CDSR $(\mathrm{r}=0.52, \mathrm{P}=0.13)$, but decreased in DARE $(\mathrm{r}=0.42$, $\mathrm{P}=0.23$ ). The burden of disease in established market economies correlated modestly with the number of reviews in the CDSR $(\mathrm{r}=0.56 ; \mathrm{P}=0.09)$; correlations in the DARE were high (overall $\mathrm{r}=0.87, \mathrm{P}<0.001$, range 0.63-0.94 across subgroups of reviews).

The number of reviews in the DARE seemed less responsive to global burden of disease than to the burden in established market economies, but the difference was not significant. The CDSR did not show this (figure).

\section{Comment}

The number of published systematic reviews is still relatively small and unevenly covers different diseases and aspects of health care. Often, millions of DALYs correspond to each available systematic review. Of course, new systematic reviews are continuously
School of Child and Adolescent Health, Red Cross

Children's Hospital, University of Cape Town, 7700

Rondebosch, South Africa

George H Swingler associate professor

Primary Health Care, Faculty of Health Sciences, University of Cape Town, Cape Town Jimmy Volmink professor

Clinical Trials and Evidence-Based Medicine Unit, Department of Hygiene and Epidemiology, University of Ioannina School of Medicine, Ioannina 45110, Greece

John P A Ioannidis chairman

Correspondence to: $\mathrm{J}$ P A Ioannidis jioannid@cc.uoi.gr

BMJ 2003;327:1083-4

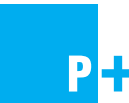

The disease categories in the figure are in order on bmi.com 